\title{
Testing the WEAP Hydrologic Model for Awash Basin, Ethiopia "Soil Moisture Module with Watershed Demand Approach"
}

\author{
Sisay Teklu*, Ahmed H. Soliman and Alaa El-Zawahry \\ Irrigation and Hydraulics Department, Faculty of Engineering, Cairo University, Egypt \\ *E-mail of the corresponding author: sisay_teklu@yahoo.com
}

The research is financed by the Egyptian Government through the Nile Sector bilateral cooperation project

\begin{abstract}
Currently, there are several hydrological simulation models in use worldwide. Prior to adoption of a model to a specific basin, its feasibility and practicality should be tested. This study highlights on the application of Water Evaluation and Planning system (WEAP) model for hydrologic simulation of Awash river basin in Ethiopia. A monthly time step hydrologic model was developed using the soil moisture rainfall-runoff method incorporated in WEAP with an aim to check the suitability of the model for Awash river basin. For this purpose five selected flow gauge stations located at the upper, middle and lower Awash basin were used as control stations. The model is configured taking into account the effects of development and hence the water abstractions, storage, loss rate, etc. are estimated using the data provided through various kinds of research and survey in Ethiopia. Standard methods are also used to prepare the hydro-metrological and landuse input data for each sub-catchment. Based on data availability, the time period 1986-2005 was selected for the hydrologic simulation. The observed data were split for calibration (1986-1995) and validation (1996-2005) purposes. Initially, the model was set up using the default model parameters. Then, manual calibration is performed to reproduce the observed streamflow. The modelsimulated values are compared with those obtained from observations using standard statistical tests on monthly and monthly average basis. From the performance test results, it is observed that the coefficient of determination $\left(\mathrm{R}^{2}\right)$ and the Index of Agreement (IA) show a good fit. Furthermore, the Nash-Sutcliffe Efficiency (NSE) and the Percent Bias (PBIAS) calibration and validation results show good performance for Upper Awash stations and satisfactory results for the middle and lower Awash control stations. As a conclusion, the main modelling constraints were discussed and possible solutions were also suggested in order to improve the performance of water resources simulation models for the Awash basin.
\end{abstract}

Keywords: Awash Basin, Hydrologic Simulation, Calibration, Validation, Model Performance, WEAP

DOI: $10.7176 / \mathrm{CER} / 12-3-07$

Publication date: March $31^{\text {st }} 2020$

\section{Introduction}

The Awash River originates from the high plateau to the west of Addis Ababa at an elevation of about 3,000 m above mean sea level (a.m.s.l.) in the central Ethiopian highlands. It then flows eastwards along the Rift Valley and terminates in saline Lake Abe at elevation of 250 a.m.s.l. at the border with Democratic Republic of Djibouti. The annual runoff within the basin is estimated at $4.9 \mathrm{Bm}^{3}$ (Halcrow, 1989). It has a total area of $114,000 \mathrm{~km}^{2}$ with a total length of 1,200 km. The landscape of the basin comprises highlands, escarpment and rift valley.

Awash river basin is the most developed and utilized basin in the country (Awulachew et al., 2007). The water demand in the basin is expanding due to population growth, rapid socio-economic development and increased irrigation expansion activities. On the other hand, the supply resources of basin are shrinking due to reservoir sedimentation, pollution and climate change impacts. The cumulative impact of these factors is leading the basin to water scarcity and water use conflicts among different water use sectors (Parker et al., 2016). In order to address these problems and improve the water resources management practices, the current and future water availability in terms of quantity, quality and spatial occurrence should be studied in depth in the first place. Then, an efficient water allocation mechanism should be established taking into account the different water use sectors including the environment. This can be realized manly through employing water resources simulation and planning models which are suitable for the basin. 
The Water Evaluation and Planning System (WEAP) is an Integrated Water Resources Management (IWRM) model developed by the Stockholm Environmental Institute. WEAP has advantage over other simulation models in that it can be used for hydrologic simulation as well as scenario analysis and water allocation. WEAP can be considered as one of the potential modelling tools for the Awash river basin. However, prior to its adoption the suitability should be tested. Hence, the objective of this study is to develop a hydrologic model of the Awash basin using WEAP with the main goal of determining the feasibility and practicality of the WEAP hydrologic model for the entire Awash basin. Based on physical and socio-economic factors, Awash basin is divided into four distinct zones. These are Upper Awash (UA), Upper Valley (UV), Middle Valley (MV) and Lower Valley (LV). The location map of the study area is presented in Figure 1.

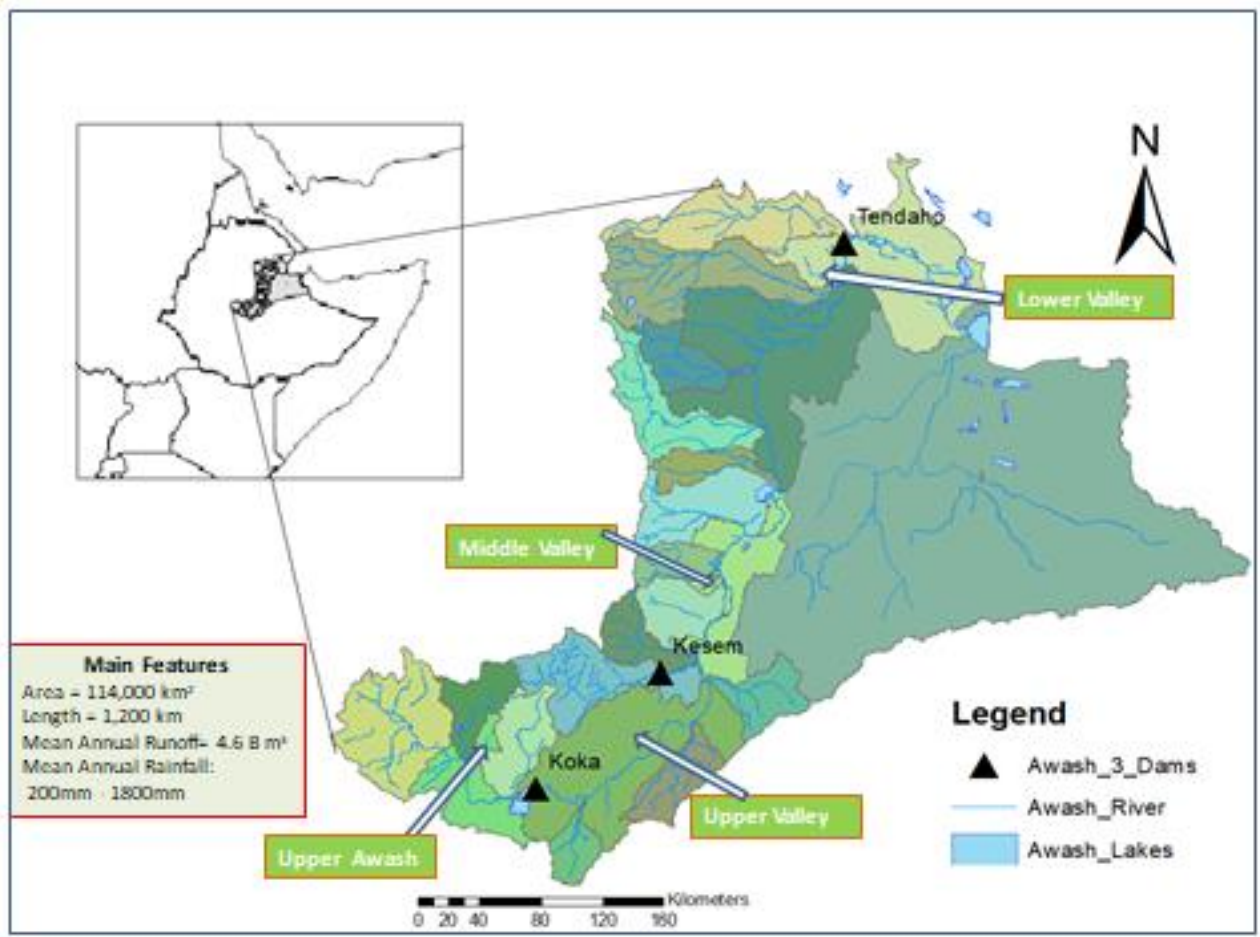

Figure1: Map of the Awash River Basin, Ethiopia

\section{Materials and Methods}

\subsection{Model Description}

There are three hydrologic modeling methods in WEAP (SEI, 2015). They are: 1) The Rainfall Runoff Method Food and Agriculture Organization (FAO); 2) The FAO - Irrigation Demands Only, and 3) The Rainfall Runoff Soil Moisture Method. For this study, the soil moisture rainfall-Runoff method is used for simulation of the hydrologic process of the Awash basin. The method is formulated based on an algorithm of one dimensional - two soil layer conceptual model for calculating surface runoff, evapotranspiration, deep percolation and sub-surface runoff for a defined unit area of land (Yates et al., 2005). The hydrologic process mass balances are described in Equation 1, and the corresponding conceptual model diagram is demonstrated using Figure 2 below.

The hydrologic process mass balance equation is written as:

$S w_{j} \frac{d z_{1, j}}{d t}=P_{e}(t)-P E T(t) k_{c, j}(t)\left(\frac{5 z_{1, j}-2 z_{1, j}^{2}}{3}\right)-P_{e}(t) z_{1, j}^{R R F_{j}}-f_{j} k_{s, j} z_{1 . j}^{2}-\left(1-f_{j}\right) k_{s, j} z_{1 . j}^{2}$ 
Where,

$S w_{j}=$ soil water holding capacity of area $\mathrm{j}(\mathrm{mm})$

$z_{1, j}=$ relative water storage in the root zone layer in area $\mathrm{j}$

$P_{e}(\mathrm{t})=$ effective precipitation at time $\mathrm{t}(\mathrm{mm})$

PET $(\mathrm{t})=$ reference potential evapotranspiration $(\mathrm{mm} /$ day $)$

$k_{c, j}=$ crop coefficient for area $\mathrm{j}$

$R R F_{j}=$ Runoff resistance factor for area $\mathrm{j}$

$f_{j} \quad=$ horizontal and vertical flow partitioning coefficient

$k_{s, j}=$ saturated hydraulic conductivity of the root zone layer for area $\mathrm{j}$ ( $\mathrm{mm} /$ time)

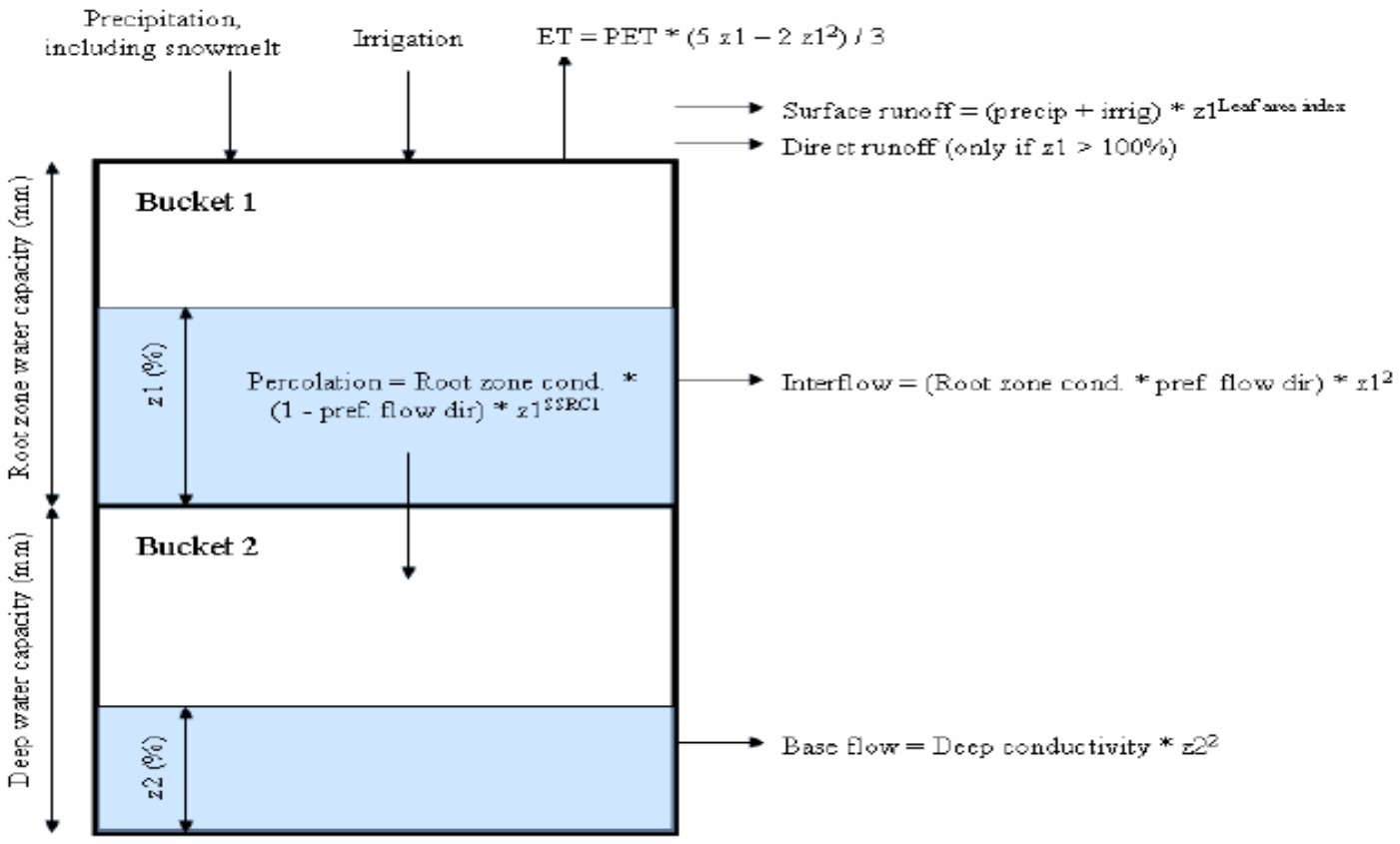

Figure 2: WEAP Soil Moisture Model (Source: SEI, 2015)

\subsection{Study Definition}

Several steps are included in the application of WEAP. The study definition sets up the time frame, spatial boundary, system components and configuration of the problem (SEI, 2015). In WEAP models are called 'Areas". Areas are limited by boundaries, which define the extent of the project area. Initially, the geographic area of the project is selected from the world map that is situated in the Schematic View. Once the Area is created the next step is to set the general parameters. This includes mainly the time frame and the time steps. For this study monthly time step is selected with the years 1986 and 2005 as the starting and end years of simulation period.

\subsection{Input Data}

The input data for WEAP hydrologic simulation modelling is comprised of two broad categories namely "Catchments \& Demand Sites" and "Supplies \& Resources". The catchments \& demand sites category includes user defined variables and default or calibratable parameters. The user defined parameters mainly include catchment area, landuse group, crop coefficient, precipitation, climate, water abstractions or demands and others. The default or calibratable parameters are those parameters which are used in the mass balance equation and derived from the landuse group and soil data. The supply \& resources category consists of mainly user defined variable such as reservoirs, streamflow, flow requirements, transmission links, return flows and others. The data together with derived parameters and the input techniques employed are briefly discussed as follows. 


\subsection{Catchments and demand sites}

\subsubsection{Catchments}

I. User defined variables

a) Catchment Area

The catchment area is a fundamental parameter of any hydrologic model (Amato et. al., 2006). ArcMap 10.3 software and STRM 90 DEM (Digital Elevation Model) were used to delineate twenty two sub-basins in the Awash basin river system. The shapefile of the sub-basins and the main rivers of Awash river basin were added to the WEAP schematic by first exporting the shapefile from the ArcMap and then adding them to WEAP as a vector layer of the basin. The rivers were then drawn in WEAP by tracing over the vector layer and the other schematic elements were placed using the "drag and drop" facility. The sub-basins, the corresponding areas and the resulting WEAP model schematic of Awash river basin is shown in Figure 3.

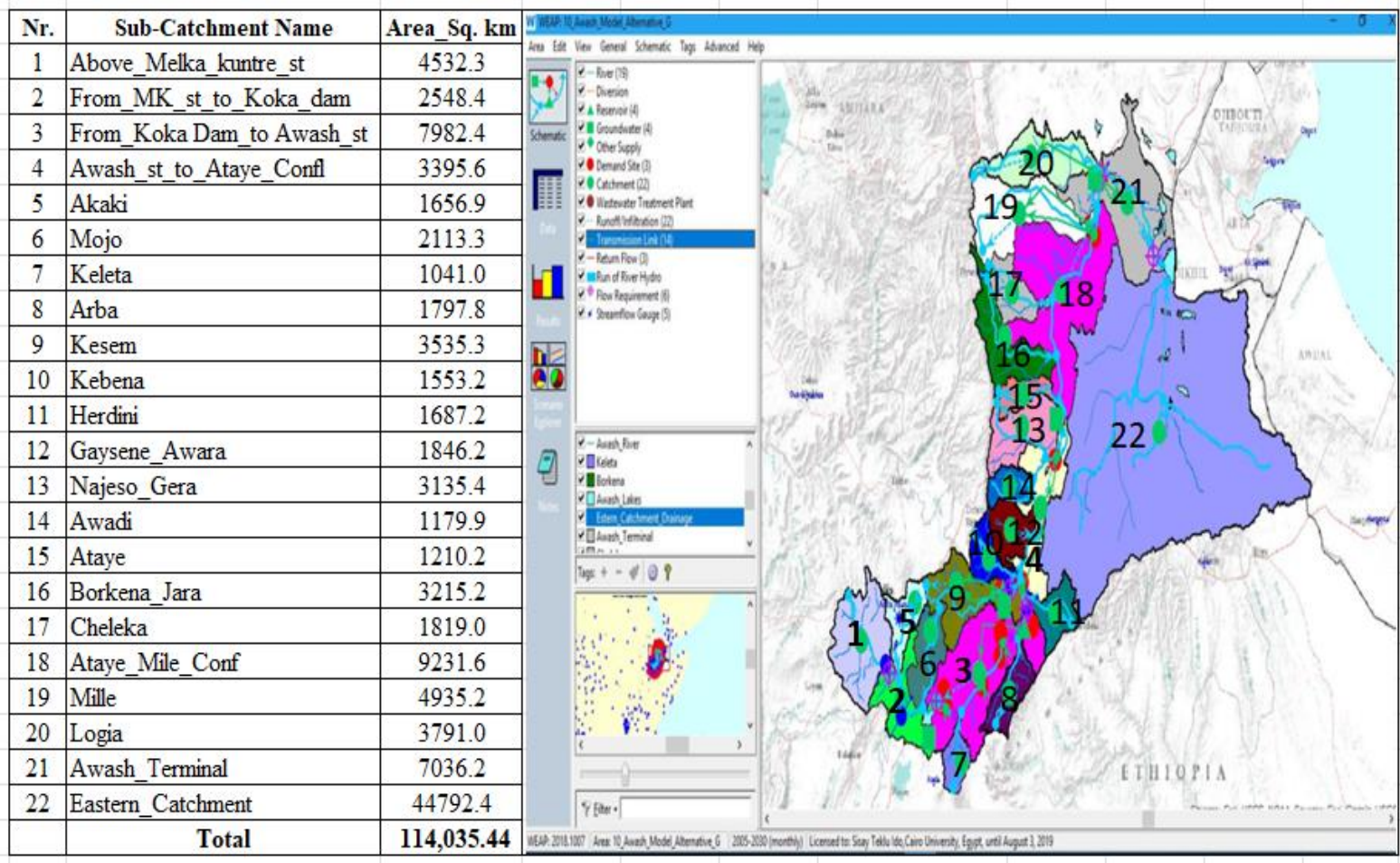

Figure 3: Awash Sub-Basins and WEAP Schematic View

\section{b) Land Use Groups}

Land use category sub divisions were created within the twenty two sub-basins. The land use classification is based on Globcover 2006 data as shown in Figure 4. The fourteen land use classes defined by Globcover were further modified and summarized to nine major classes for non-irrigated catchments. For irrigated catchments, the agriculture land use class was further divided to rainfed and irrigated agriculture based on the available irrigation data for the catchment. The area of each land use category within each sub-basin was determined as percentages of the total sub-basin area using Arc Toolbox and applied in the WEAP model as shown in Table 1 below. 


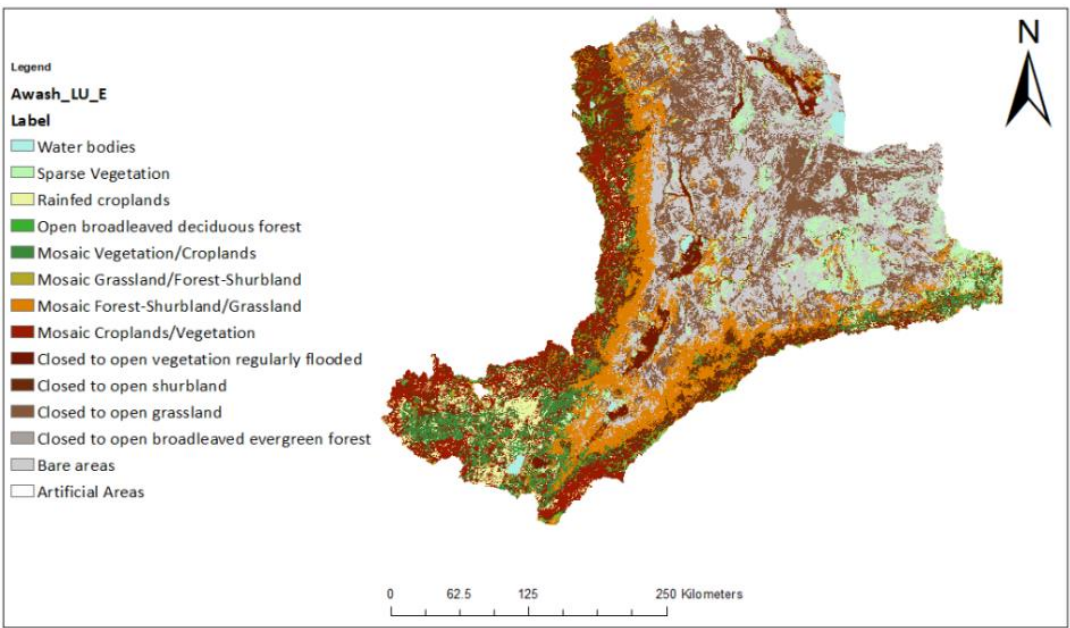

Figure 4: Awash Basin Landuse Category based on Globcover (2006)
Table 1: Landuse Category for Koka Dam to Awash Station Irrigated Catchment

\begin{tabular}{|l|c|c|}
\hline $\begin{array}{c}\text { Landuse } \\
\text { Category }\end{array}$ & $\begin{array}{c}\text { Area } \\
\text { (sq . km) }\end{array}$ & $\begin{array}{c}\text { Percent } \\
\text { Area }\end{array}$ \\
\hline Shurbland & 501.2 & 6.28 \\
\hline Agriculture/Rainfed & 1138.0 & 14.26 \\
\hline Agriculture/Irrigated & 235.04 & 2.94 \\
\hline Artificial/Urban & 9.2 & 0.12 \\
\hline Bare areas & 661.7 & 8.29 \\
\hline Forest & 4428.3 & 55.48 \\
\hline Grassland & 234.3 & 2.94 \\
\hline Sparse Vegetation & 371.6 & 4.66 \\
\hline Water bodies & 202.2 & 2.53 \\
\hline Wetland & 198.3 & 2.48 \\
\hline Unknown & 2.5 & 0.03 \\
\hline \multicolumn{1}{|c|}{ Total } & $\mathbf{7 9 8 2 . 4}$ & $\mathbf{1 0 0 . 0 0}$ \\
\hline
\end{tabular}

\section{c) Crop coefficient, $\mathrm{Kc}$}

The crop coefficient $\mathrm{Kc}$ is a parameter that is used to expresses the relative evapotranspiration difference between the reference and the cropped surface. The Kc value is dependent on the type of land class. Crop evapotranspiration is calculated by multiplying the reference evapotranspiration (ETo) by Kc. For Awash river basin, Kc values for a total of twenty land use categories and crop types were determined from different previous studies (Allen et. al., 1998, Amato et. al., 2006, Tiruneh et al., 2013). For the Kc value of each land use category, a read from CSV files and a Key Assumptions were created and applied in the WEAP model as shown in Figure 5 below.

\section{d) Precipitation}

Monthly time series precipitation data was obtained from the National Meteorology Agency of Ethiopia (NMAE). The Theissen polygon spatial analysis method was applied to twenty one selected climate stations to determine the average monthly areal precipitation for each sub-basin for the period of 1986 to 2005. A read from CSV file monthly precipitation data for each sub-basin was created and applied in the WEAP model as shown in Figure 6 below.

\section{e) Climate (Temperature, Wind, Humidity and Cloudiness Fraction)}

The other climate parameters i.e., temperature, relative humidity and wind data are entered in degrees Celsius, as a percentage and in meters per second respectively. Monthly time series temperature and wind speed dataset in 0.25 degree raster format is obtained from Princeton University data portal (Terrestrial Hydrology Group, 2014). Theissen polygon spatially weighted relative humidity mean monthly values per sub-basin was estimated using data obtained from Food and Agriculture Organization (FAO) database (CLIMWAT, n.d.). One (1) month Terra/MODIS cloudiness fraction data for five years from (2001-2005) was obtained from (NASA Earth Observations (NEO), n.d.). However, only average monthly cloudiness fraction and relative humidity data were available. Hence, the average monthly values were repeated for every corresponding month and read into WEAP as a time series expression from a CSV file.

\section{f) Others}

The other user defined parameters include the latitude at the centroid of each catchment expressed in Degree Decimal (DD) and Glacier and snow modelling parameters include melting point, freezing point, albedo with lower and upper bound. Glacier and snow modelling is not applicable for Awash river basin. Hence, WEAP default parameter values are used to run the model. 
Table 2: WEAP Parameters and Ranges of Default Values

\begin{tabular}{|c|l|c|c|c|c|}
\hline \multirow{2}{*}{ Nr. } & \multirow{2}{*}{ Parameter } & \multirow{2}{*}{ Unit } & \multicolumn{3}{|c|}{ Range of Values } \\
\cline { 4 - 6 } & & & Minimum & Maximum & Default \\
\hline 1 & Soil Water Capacity & $\mathrm{mm}$ & 0 & $>0$ & 1000 \\
\hline 2 & Deep Water Capacity & $\mathrm{mm}$ & 0 & $>0$ & 1000 \\
\hline 3 & Runoff Resistance Factor & - & 0 & 1000 & 2 \\
\hline 4 & Root Zone Conductivity & $\mathrm{mm} / \mathrm{month}$ & 0 & $>0$ & 20 \\
\hline 5 & Deep Conductivity & $\mathrm{mm} / \mathrm{month}$ & 0.1 & $>0.1$ & 20 \\
\hline 6 & Preferred Flow Direction & - & 0 & 1 & 0.15 \\
\hline 7 & InitialZ1 & $\%$ & 0 & 100 & 30 \\
\hline 8 & Initial Z2 & $\%$ & 0 & 100 & 30 \\
\hline
\end{tabular}

\subsubsection{Demand sites}

\section{a) Urban domestic demand}

This study covers only the main towns namely Awash, Nazareth and Metehara which directly abstract water from the main Awash River. The total population of the three towns for hydrologic simulation starting year 1986 and end year (year 2005) was estimated about 99,268 and 235,354 respectively as indicated in Table 3 . The annual rate of water use was estimated using a consumption rate of 100 LCD (Liter /Capita per Day). Based on the two national census data (CSA Census Report 1994, CSA Census Report 2007), the total population of the three towns is predicted to grow at a rate of 4.2 percent per annum.

Table 3: Population of Urban Domestic Demand Sites

\begin{tabular}{|c|c|c|c|c|}
\hline \multirow{2}{*}{ Nr. } & \multirow{2}{*}{ Demand Sites (Towns) } & \multicolumn{3}{|c|}{ Population by year } \\
\cline { 3 - 5 } & & 1986 & 1994 & 2005 \\
\hline 1 & Nazareth/Adama & 85481 & 127842 & 202917 \\
\hline 2 & Metehara & 7980 & 11934 & 21,348 \\
\hline 3 & Awash & 5807 & 8684 & 11053 \\
\hline \multicolumn{2}{|r|}{ Total } & $\mathbf{9 9 , 2 6 8}$ & $\mathbf{1 4 8 , 4 6 0}$ & $\mathbf{2 3 5 , 3 5 4}$ \\
\hline
\end{tabular}

(Source: CSA Census Report, 1994 \& 2007)

\section{b) Irrigation demand}

Irrigation water demands are modeled as a watershed demand. In this approach, the land cover in a sub-catchment has been designated as containing irrigated land cover fractions with lower and upper irrigation thresholds, $\mathrm{Lj}$ and $\mathrm{Uj}$ for crop $\mathrm{j}$. These thresholds show both the quantity and timing of water needed for irrigation, as the water available in the storage of the upper level $(\mathrm{Z} 1, \mathrm{j})$ depletes due to evapotranspiration and percolation. When the relative soil moisture, $\mathrm{Z} 1, \mathrm{j}$ drops below the lower threshold $\mathrm{Lj}$, an irrigation demand will be triggered in the fractional area. The total irrigation demand for each sub-catchment is the sum of irrigation demand for the fractional areas found in the sub catchment (Yates et. al. 2005).

In the present study, irrigation water demand is estimated based on the existing and potential net irrigation areas (ha) data as proposed by Ministry of Water Resources (MoWR) and Halcrow (WWDSE and WAPCOS, 2005). According to this data, irrigation schemes are aggregated into three principal groups. They are: (I) Upper Valley (UV), (II) Middle Valley (MV), and (III) Lower Valley (LV) irrigation groups. The existing and proposed irrigation areas are presented in Table 4.

During the model application, the existing irrigation data in the years 1986-2005 are used for the hydrologic simulation in order to take into account the effects of development. In order to fit with the model input format, the data in Table 4 was rearranged and organized in a sub-catchment category as shown in Table 5. Within in each subcatchment, the dominant crop types were identified and the data in Table 5 was further disaggregated based on irrigated crop area. Hence, for irrigated catchments, the irrigated crop areas were included as a component of agriculture landuse class. Like the others landuse classes, the area of each crop within each sub-catchment was 
determined as a percentage of the total sub-catchment area using Arc Toolbox and applied in the WEAP model. Table 6 demonstrates the input format used for the irrigation data at the year 1986. Similar procedures are also used for the year 2005 .

Table 4: Existing and Potential Net Irrigation Areas (ha)

as Proposed by Halcrow and MoWR (Source: WWDSE and WAPCOS, 2005)

\begin{tabular}{|c|c|c|c|c|c|c|}
\hline \multirow{2}{*}{ Irrigation Group } & \multicolumn{2}{|c|}{ Existing } & \multicolumn{2}{c|}{ Expansion Proposed } & \multicolumn{2}{c|}{ Total } \\
\cline { 2 - 7 } & Halcrow & MoWR & Halcrow & MoWR & Halcrow & MoWR \\
& 1989 & 2005 & 1989 & 2005 & 1989 & 2005 \\
\hline Upper Valley & 23284 & 23504 & 10626 & 17903 & 33910 & 41407 \\
\hline Middle Valley & 21896 & 14591 & 36320 & 20000 & 58216 & 34591 \\
\hline Lower Valley & 25600 & 11600 & 36900 & 48000 & 62500 & 59600 \\
\hline Total & $\mathbf{7 0 , 7 8 0}$ & $\mathbf{4 9 , 6 9 5}$ & $\mathbf{8 3 , 8 4 6}$ & $\mathbf{8 5 , 9 0 3}$ & $\mathbf{1 5 4 , 6 2 6}$ & $\mathbf{1 3 5 , 5 9 8}$ \\
\hline
\end{tabular}

Table 5: Existing Net Irrigation per Sub-catchments and Irrigation Groups

\begin{tabular}{|c|c|c|c|c|}
\hline \multirow{2}{*}{ Irrigation Group } & \multirow{2}{*}{ Irrigation Sub-Group } & \multirow{2}{*}{ Sub-Catchments } & \multicolumn{2}{|c|}{ Irrigation Area (ha) } \\
\hline & & & $1986 / 88$ & 2005 \\
\hline \multirow{3}{*}{ Upper valley (UV) } & (UV1)Upper Valley Irrigation_1 & \multirow{3}{*}{ Koka Dam-Awash Station } & 7,001 & 8,203 \\
\hline & (UV2)Upper Valley Irrigation_2 & & 7,323 & 5,083 \\
\hline & (UV3)Upper Valley Irrigation_3 & & 8,960 & 10,218 \\
\hline & Total & & 23,284 & 23,504 \\
\hline \multirow{3}{*}{ Middle Valley (MV) } & (MV1)Middle Valley_1 & Kesem & 1,915 & 1,915 \\
\hline & (MV2)Middle Valley_2 & \multirow{2}{*}{ Awash St - Ataye Conflunce } & 17,410 & 8,590 \\
\hline & (MV3)Middle Valley_3 & & 2,571 & 4,086 \\
\hline & Total & & 21,896 & 14,591 \\
\hline \multirow{4}{*}{ Lower Valley (LV) } & \multirow{2}{*}{ (LV1)Lower Valley_1 } & Mille & 1,440 & 1,440 \\
\hline & & Logia & 160 & 160 \\
\hline & (LV2)Lower Valley_2 & \multirow{2}{*}{ Awash Terminal } & 15939 & 6000 \\
\hline & (LV3)Lower Valley_3 & & 8,061 & 4,000 \\
\hline \multicolumn{3}{|c|}{ Total } & 25,600 & 11,600 \\
\hline \multicolumn{3}{|c|}{ Basin Total } & $\mathbf{7 0 , 7 8 0}$ & 49,695 \\
\hline
\end{tabular}

\subsection{Supply and resources}

\subsubsection{Reservoirs}

The reservoir simulation in WEAP takes into account net evaporation on the reservoir, priorities of downstream requirements, hydropower energy demands, and the reservoir's operating rules. The only reservoir that is active during the simulation period is that of Koka dam. Koka dam is located in the upper valley region of the basin. It is a a multipurpose dam for hydropower production and flood regulation. The installed and firm capacity of Koka power house is 43.2 MW and $30 \mathrm{MW}$ respectively (Halcrow, 1989). Initially, Koka dam was constructed and operated primarily for hydropower generation. Later on, the release from the dam has become the main source of water for the irrigation schemes downstream of the dam. During modelling the reservoir, the net evaporation, the reservoir elevation-area-capacity curve and other parameters data are adapted from previous researches (WWDSE and WAPCOS, 2005, Halcrow, 1989).

\subsubsection{Streamflow gauges}

Stream flow data was obtained from the hydrology department of Ministry of Water, Irrigation and Energy of Ethiopia. Five locations were selected as comparison points between the simulated and observed flows. Four out of five stations are located on the main Awash river and one station is located on the tributary Kesem river. These particular gauges were selected based on data availability and considering spatial distribution to cover the upper, middle and downstream reaches of the river basin as shown in Figure 7. 


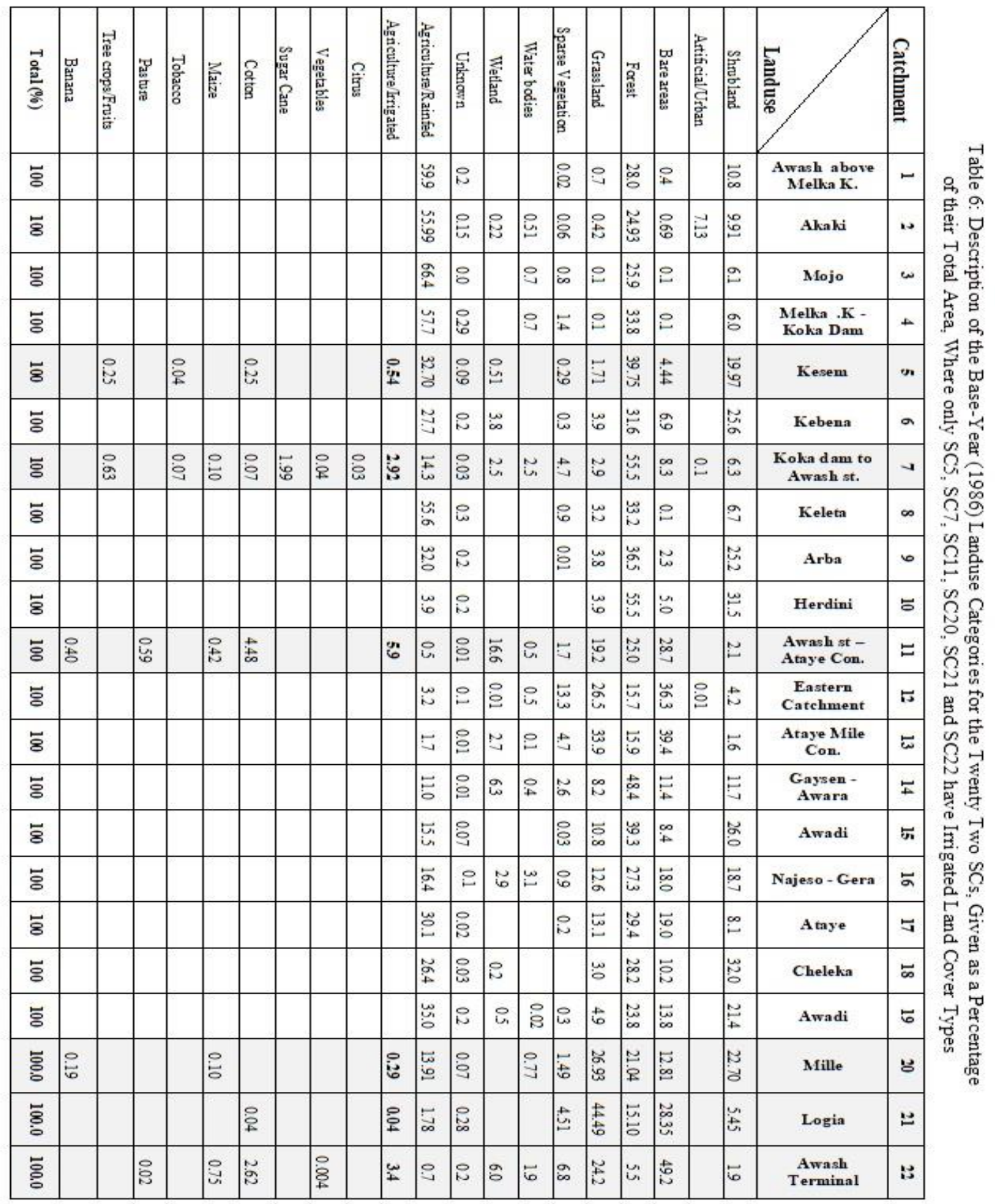




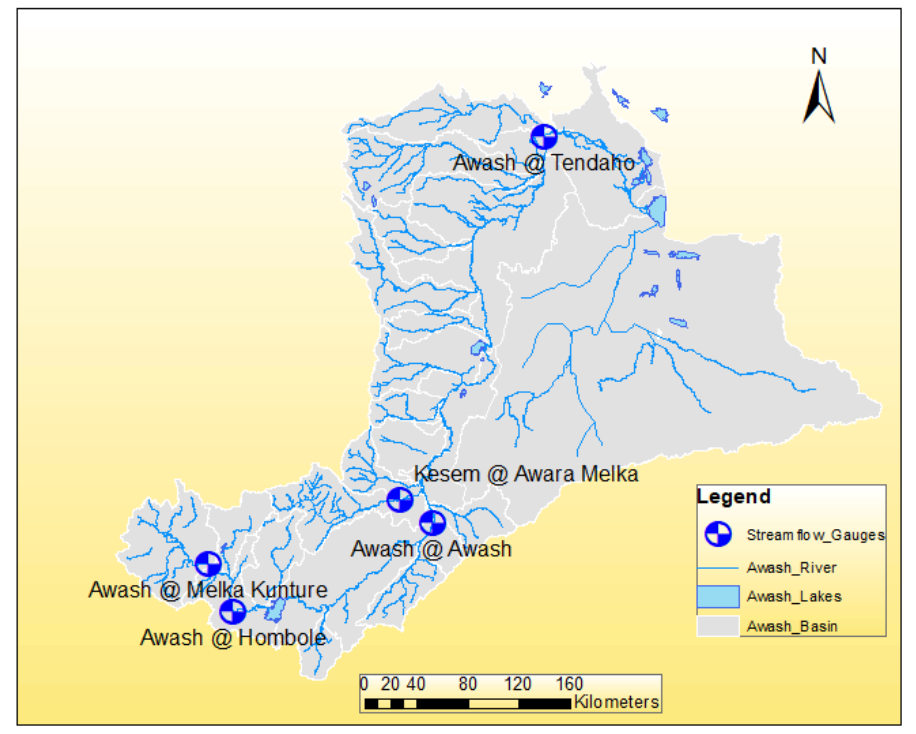

Figure 7: Location of Control Stations

\subsubsection{Transmission links and return flows}

Transmission links are used to connect the supply systems to each demand site. On the other hand, return flow links are used to connect the outflows from the demand sites back to the rivers. The return flow is determined as the balance between the inflow to a demand site and its consumption (the portion of the inflow that lost in the system). In this study, transmission links are established for all domestic demand sites and catchments. A $50 \%$ return flow is also assumed for the three (3) urban domestic water demand site nodes.

\subsection{Model calibration and validation}

Initially, the default model parameters were used to set up the model. Based on data availability, the time period 1986-2005 was selected for the hydrologic simulation. The model was calibrated for the first 10 years period (1986-1995) and validated for the second 10 years period (1996-2005). However, the time span varies from one station to another depending on stream flow data availability as described in the results summary Table 8 . The calibration and validation involved both quantitative and qualitative evaluation of the hydrologic response at the control stations. A Key Assumption of default parameter values was created for each sub-basin in the data entry view of the WEAP model as shown in Figure 8 . The parameters were adjusted manually to reproduce the monthly and monthly average stream flow patterns.

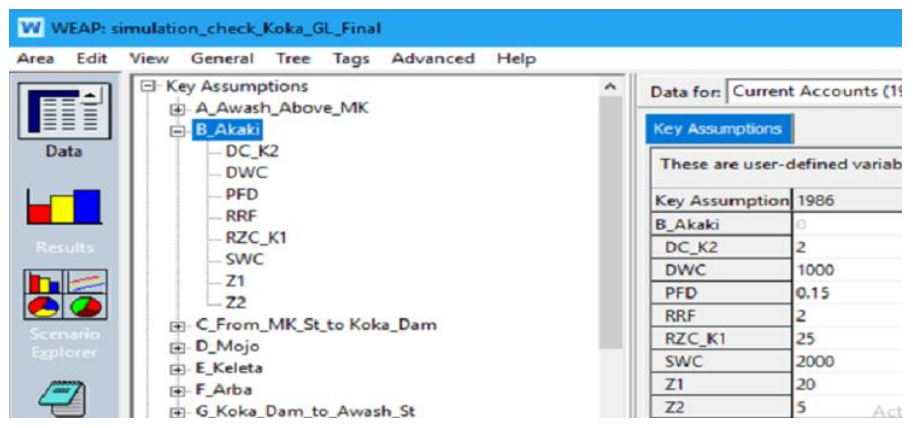

Figure 8: A Key Assumption Value of Parameters for Akaki Sub-catchment 


\subsection{Model Performance Tests}

The performance of the hydrologic model was tested using standard statistical tests supported with visual inspection of the time series plots. The statistical parameters employed for the test include Coefficient of determination $\left(\mathrm{R}^{2}\right)$, Nash-Sutcliffe Coefficient (NSE), the Index of Agreement (IA) and the Percent BIAS (PBIAS). Details on efficiency criteria for the assessment of hydrological model are provided in Krause, et al. (2005). The model performance criteria employed in the present study are briefly described as follows:

\subsubsection{Coefficient of Determination $\left(R^{2}\right)$}

The coefficient of determination $\left(R^{2}\right)$ is a measure of how well the regression model describes the observed data (Schneider et al., 2010). It is the square of the Pearson's coefficient of correlation (R) between two variables i.e., observed and simulated streamflows in our case. The closer $\mathrm{R}^{2}$ to 1 indicates better fit or relationship, between the two variables.

$$
R^{2}=\left(\frac{\left(\sum_{i=1}^{n}\left(Q_{o_{i}}-\overline{Q_{o}}\right)\left(Q_{s_{i}}-\overline{Q_{s}}\right)\right)}{\sqrt{\sum_{i=1}^{n}\left(Q_{o_{i}}-\overline{Q_{o}}\right)^{2}} \sqrt{\sum_{i=1}^{n}\left(Q_{s_{i}}-\overline{Q_{s}}\right)^{2}}}\right)^{2}
$$

\subsubsection{Index of Agreement (IA)}

The index of agreement (IA) is used as a test of how well the simulated data fit with the observed one. It is a measure of the degree to which a model's predictions are error free (Cort J. W., 1981). Its value varies from 0 to 1 ; closer value to 1 indicates a better fit of simulated and observed stream flows.

$$
I A=1.0-\left(\frac{\sum_{i=1}^{n}\left(Q_{o_{i}}-Q_{S_{i}}\right)^{2}}{\sum_{i=1}^{n}\left(\left|\left(Q_{S_{i}}-\overline{Q_{o}}\right)\right|-\left|\left(Q_{o_{i}}-\overline{Q_{o}}\right)\right|\right)^{2}}\right)
$$

\subsubsection{Nash-Sutcliffe Coefficient (NSE)}

Nash and Sutcliffe (1970) proposed an Efficiency Coefficient (NSE) as expressed in Eqn. 4 below. Its value ranges from minus infinity to 1.0 , with high values indicating better agreement. An efficiency NSE= 1 indicates a perfect fit of simulated and observed data.

$$
N S E=1.0-\left(\frac{\sum_{i=1}^{n}\left(Q_{o_{i}}-Q_{S_{i}}\right)^{2}}{\sum_{i=1}^{n}\left(Q_{o_{i}}-\overline{Q_{o}}\right)^{2}}\right)
$$

\subsubsection{Percent Bias (PBIAS)}

PBIAS (\%) measures the average tendency of the simulated flows to be larger or smaller than their corresponding observed values. The optimal value is 0 . 0 , positive and negative values indicate a model bias toward underestimation and overestimation respectively (Gupta et al., 1999). PBIAS is calculated as:

$$
P B I A S=\left(\frac{\sum_{i=1}^{n}\left(Q_{o_{i}}-Q_{s_{i}}\right) * 100}{\sum_{i=1}^{n}\left(Q_{o_{i}}\right)}\right)
$$

Where:

$$
\begin{array}{lc}
\overline{Q_{o}}\left(\overline{Q_{s}}\right)=\text { Average observed (simulated) streamflow }\left(\mathrm{m}^{3} / \mathrm{s}\right) & \mathrm{Q}_{\mathrm{s}_{\mathrm{i}}}=\text { Simulated streamflow }\left(\mathrm{m}^{3} / \mathrm{s}\right) \\
\mathrm{Q}_{\mathrm{O}_{\mathrm{i}}}=\text { Observed streamflow }\left(\mathrm{m}^{3} / \mathrm{s}\right) & \mathrm{n}=\text { Number of data used in the analysis }
\end{array}
$$




\subsubsection{Model Performance Ratings}

The model performances with regard to the Nash-Sutcliffe Coefficient (NSE) and Percent Bias (PBIAS) tests are evaluated based on the general performance rating values Table 7 which is a result of the work of Moriasi et al. (2007).

Table 7: General Performance Ratings for Recommended Statistics for a Monthly Time Step

\begin{tabular}{lccccc}
\hline Performance & \multirow{2}{*}{ RSR } & \multirow{2}{*}{ NSE } & \multicolumn{3}{c}{ PBIAS $(\%)$} \\
\cline { 3 - 5 } \multicolumn{1}{c}{ Rating } & & & Streamflow & Sediment & N.P \\
\hline Very good & $0.00<\mathrm{RSR} \leq 0.50$ & $0.75<\mathrm{NSE} \leq 1.00$ & PBIAS $< \pm 10$ & PBIAS $< \pm 15$ & PBIAS $< \pm 25$ \\
Good & $0.50<\mathrm{RSR} \leq 0.60$ & $0.65<\mathrm{NSE} \leq 0.75$ & $\pm 10 \leq$ PBIAS $< \pm 15$ & $\pm 15 \leq$ PBIAS $< \pm 30$ & $\pm 25 \leq$ PBIAS $< \pm 40$ \\
Satisfactory & $0.60<\mathrm{RSR} \leq 0.70$ & $0.5<\mathrm{NSE} \leq 0.65$ & $\pm 15 \leq$ PBIAS $< \pm 25$ & $\pm 30 \leq$ PBIAS $< \pm 55$ & $\pm 40 \leq$ PBIAS $< \pm 70$ \\
Unsatisfactory & RSR $>0.70$ & NSE $\leq 0.5$ & PBIAS $\geq \pm 25$ & PBIAS $\geq \pm 55$ & PBIAS $\geq \pm 70$ \\
\hline
\end{tabular}

(Source: Moriasi et al. (2007))

\section{Results and discussion}

The monthly data calibration and validation statistics at each control station and the calibrated parameters for each sub-catchment are presented in Table 8 and Table 9 respectively. The calibration stage simulation and correlation plots are also demonstrated in Figure 9.

From Table 8 , the Coefficient of Determination $\left(\mathrm{R}^{2}\right)$ values vary in the ranges of $(0.59-0.88)$ and (0.60 - 0.93), and the Index of agreement (IA) values vary in the ranges of (0.83 - 0.96) and (0.86 - 0.98$)$ for the calibration and validation stages respectively. In a similar manner, the Nash-Sutcliffe Efficiency (NSE) values vary in the ranges of $(0.5-0.86)$ and $(0.55-0.93)$ and the Percent BIAS (PBIAS) values vary in the ranges of $(-0.34-(-16.5))$ and $(-1.3-(-20.1))$ for the calibration and validation stages respectively. From the statistical analysis, it is also observed that the calibration and validation results fall within a more or less similar ranges. With regard to $\mathrm{R}^{2}$ and NSE, the upstream stations (Melka kuntre, Hombole and Kesem) show very good performance results while the middle and lower valley stations (Awash Station and Tendaho respectively) show satisfactory results. With regard to IA, the upstream stations show very good performance results while the middle and lower valley stations show good results. With regard to PBIAS, the upstream stations (Melka kuntre and Hombole) and the Middle Valley (Awash Station) show very good performance results. Kesem station shows satisfactory result during calibration and very good result at validation. Similarly, Tendaho station shows good and satisfactory result during the calibration and validations stages respectively.

Table 8: Monthly Data Calibration and Validation Statistics

\begin{tabular}{|c|l|c|c|c|c|c|}
\hline \multirow{2}{*}{ Nr. } & \multirow{2}{*}{ Statistical Parameter } & \multicolumn{5}{c|}{ Gauge Station } \\
\cline { 3 - 7 } & & Melka Kuntre & Hombole & Kesem & Awash Station & Tendaho \\
\hline 1 & Calibration Duration & $\mathrm{Jan} / 86-\mathrm{Dec} / 95$ & $\mathrm{Jan} / 86-\mathrm{Dec} / 93$ & $\mathrm{Jan} / 89-\mathrm{Dec} / 97$ & $\mathrm{Jan} / 86-\mathrm{Dec} / 94$ & $\mathrm{Jan} / 88-$ Dec/94 \\
\hline 2 & Validation Duration & $\mathrm{Jan} / 96-\mathrm{Dec} / 2005$ & $\mathrm{Jan} / 94-\mathrm{Dec} / 2000$ & $\mathrm{Jan} / 98-\mathrm{Dec} / 2005$ & $\mathrm{Jan} / 95-\mathrm{Dec} / 2003$ & $\mathrm{Jan} / 95-\mathrm{Dec} / 2001$ \\
\hline 3 & Nr. of Years & $\mathbf{1 0}(\mathbf{1 0})$ & $\mathbf{8 ( 7 )}$ & $\mathbf{9 ( 8 )}$ & $\mathbf{9}(\mathbf{9})$ & $\mathbf{7}(\mathbf{7})$ \\
\hline 4 & Nr. of Months & $\mathbf{1 2 0}(\mathbf{1 2 0})$ & $\mathbf{9 6}(\mathbf{8 4})$ & $\mathbf{1 0 8}(\mathbf{9 6})$ & $\mathbf{1 0 8}(\mathbf{1 0 8})$ & $\mathbf{8 4}(\mathbf{8 4})$ \\
\hline 5 & Coefficient of Determination $\left(\mathrm{R}^{\wedge} 2\right)$ & $0.88(0.93)$ & $0.86(0.91)$ & $0.8(0.76)$ & $0.6(0.63)$ & $0.59(0.60)$ \\
\hline 7 & Index of Agreement (IA) & $0.96(0.98)$ & $0.96(0.96)$ & $0.94(0.93)$ & $0.87(0.88)$ & $0.83(0.86)$ \\
\hline 6 & Nash-Sutcliffe Efficiency (NSE) & $0.82(0.93)$ & $0.86(0.80)$ & $0.78(0.76)$ & $0.5(0.62)$ & $0.55(0.55)$ \\
\hline 8 & Percent Bias (PBIAS) $(\%)$ & $-5.8(10.4)$ & $-0.34(-3.7)$ & $-0.16 .5(-8.5)$ & $-0.9 .2(-1.3)$ & $11.4(-20.1)$ \\
\hline
\end{tabular}




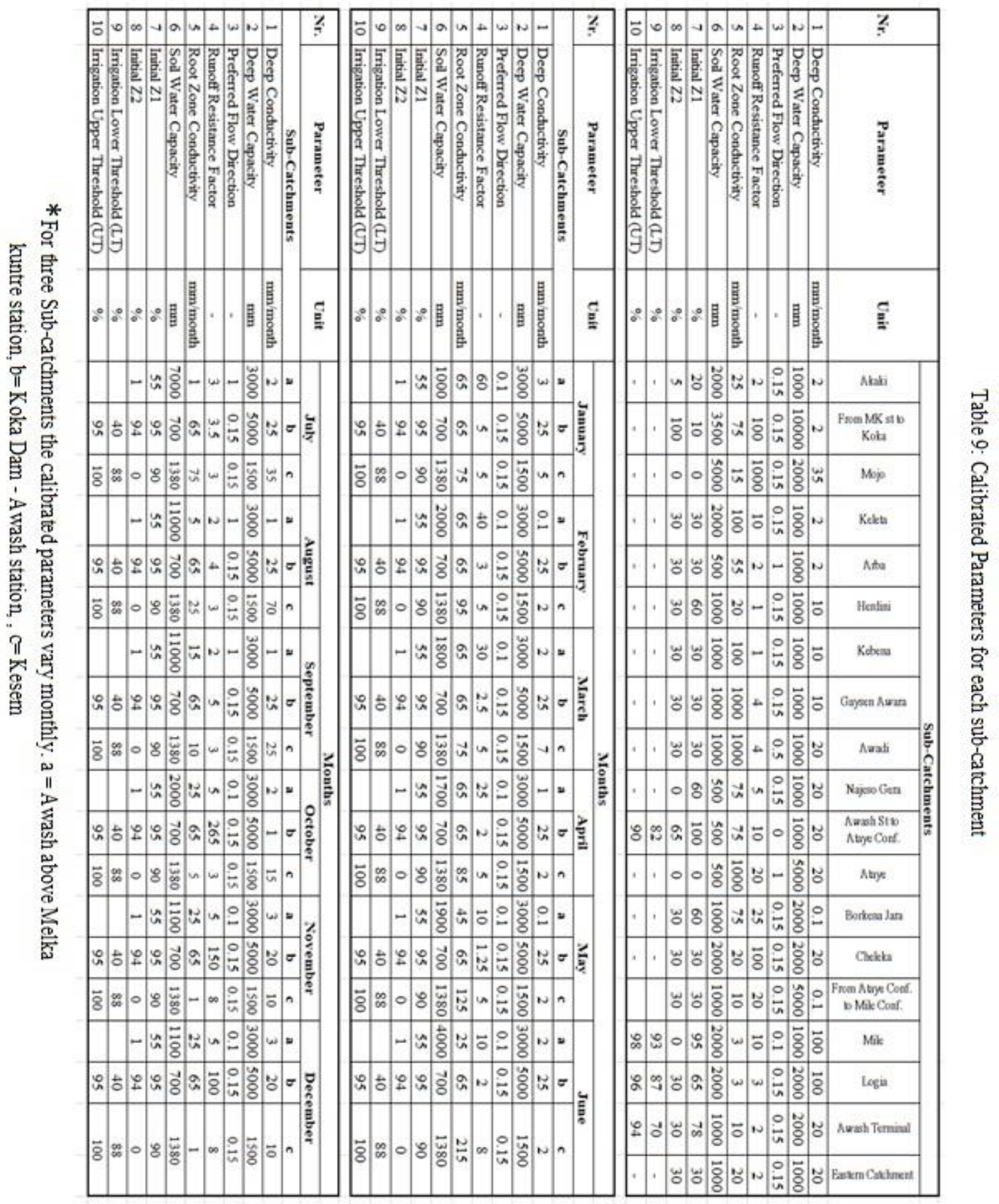



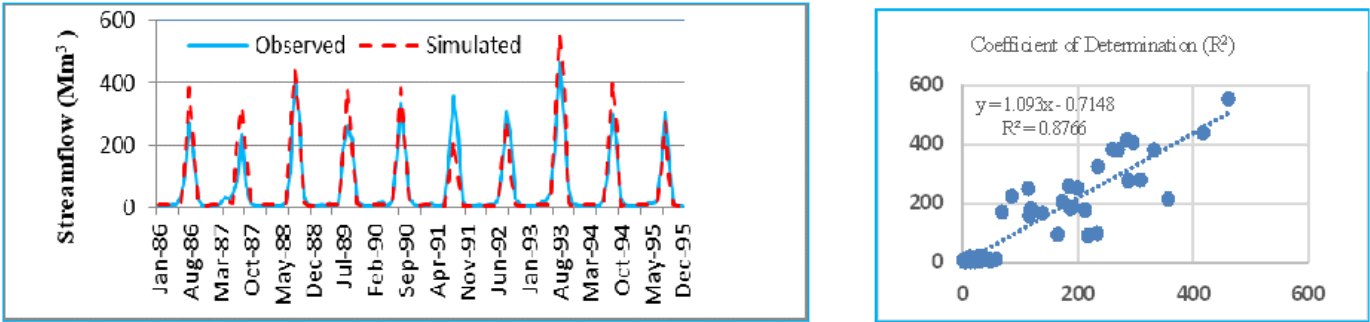

a) Awash @ Melka kuntre
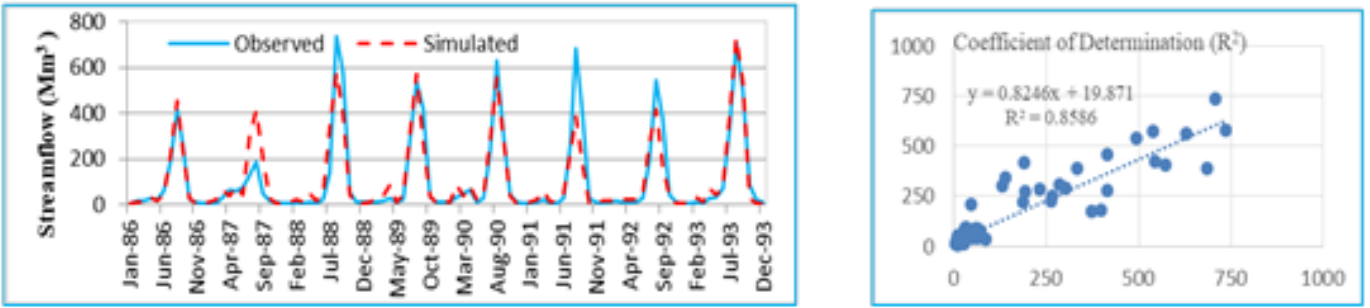

b) Awash @ Hombole
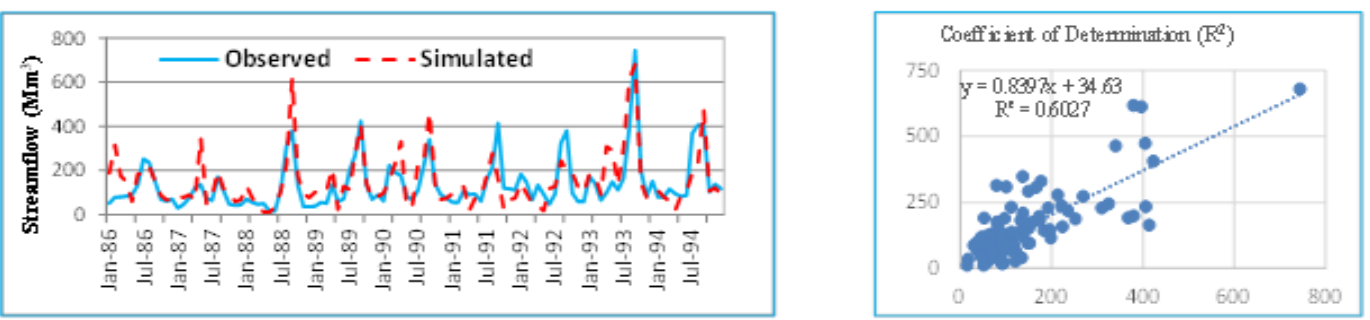

c) Awash@Awash Station
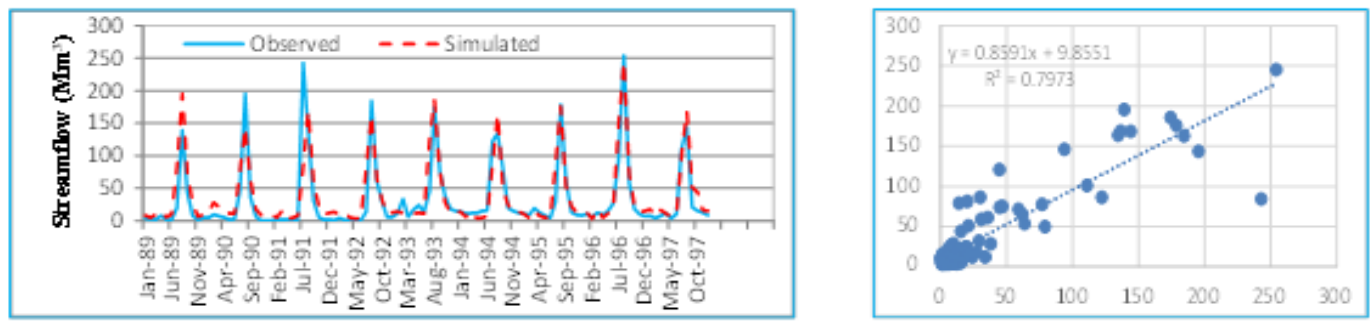

d) Kesem @ Awara Melka
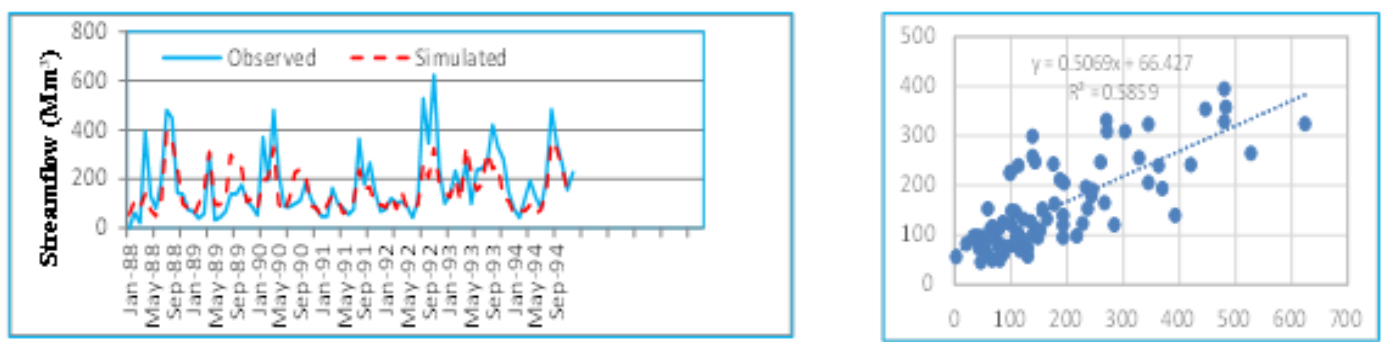

e) Awash @ Tendaho

Figure 9: Monthly Calibration and Correlation Plots 
The calibration stage observed and simulated monthly flows for the control stations are shown in Figures 9 (a) through (e). Figure 9 (a) is a plot of the monthly observed and simulated stream flow for Melka kuntre station at the upper reach of Awash basin (period from Jan 1986 to Dec 1995). In this stream gauge, compared to the observed peak flows, the model simulated higher peaks in $60 \%$ of the total number of calibration months. However, the baseflows are well simulated in all calibration months.

Figure 9 (b) is a plot of the monthly observed and simulated stream flow for Hombole station at the upper reach of Awash basin (period from Jan 1986 to Dec 1993). In this stream gauge, the model underestimates peak flows in $37 \%$ of the total number of calibration months. $12 \%$ of the peak flow show over estimation. However, the observed and simulated baseflows are comparable in all calibration months.

Similar behavior is observed in Kesem gauge station whose tendency can be seen in Figure 9 (d). However, the differences between observed and simulated flows are more significant and noticeable in the Awash station and Tendaho gauge stations in Figure 9 (c) and Figure 9 (e) respectively. The low model performance at Awash station may be due to the impacts of the irrigation abstractions and Koka dam regulation effect at the upper and middle valley reaches of the basin. While, at Tendaho gauge station the low model performance may be due to the losses and regulation effect of the Gedebassa swamp.

\section{Conclusions}

Four model performance tests, namely, the Coefficient of Determination $\left(\mathrm{R}^{2}\right)$, the Index of Agreement (IA), the Nash-Sutcliffe Coefficient (NSE) and the Precinct Bias (PBIS) were used to evaluate the applicability of the WEAP hydrologic model for Awash river basin. Of the 5 control stations used for hydrologic simulation, three stations (Awash at Melka kuntre, Awash at Hombole and Kesem at Awara melka) show a good performance. While the other two control stations (Awash at Awash station and Awash at Tendaho) show satisfactory performance. The water resources system of the Awash basin is complex. The physical characteristic of the basin is comprised of the highlands and the rift valley system that results in a wide temporal and spatial variation of both climatic and hydrologic variables throughout the basin. The basin is also the most utilized basin in terms of irrigation development. The upper and middle valley reaches of the basin are highly impacted by the irrigation abstractions and Koka dam regulation. The lower valley reach flow is also significantly influenced by the losses at the Gedebassa swamp. However, the current understanding about the basin's water resources is limited. The seepage and leakage of Koka dam, the surface-ground water interaction and the loss at the Gedebassa swamp system are not well understood. Moreover, lack of reliable quality stream flow record and water abstraction data is a main challenge. Under these circumstances, the modelling result obtained in this study is acceptable and can be used to reasonably simulate the water resources system of the river basin. Better understanding of the complex system of the Awash basin and improving the data quality can help to attain better model performance results.

\section{References}

Allen, R.G., Pereira, L.S., Raes, D., Smith, M. (1998), "Crop evapotranspiration guidelines for computing crop water requirements”, FAO Irrigation and drainage paper 56, Food and Agriculture Organization, Rome.

Amato, C. C., McKinney D. C., Ingol-Blanco E., and. Teasley R. L. (2006), "WEAP Hydrology Model Applied: The Rio Conchos Basin", CRWR Online Report 06-12, Center for Research in Water Resources, University of Texas, Austin, http://www.crwr.utexas.edu/reports/2006/rpt06-12.shtml.

Awulachew, S. B.; Yilma, A.D. Loulseged, M.; Loiskandl, W., Ayana, M.; Alamirew, T. (2007), "Water Resources and Irrigation Development in Ethiopia", Colombo, Sri Lanka: International Water Management Institute.78p. (WorkingPaper123).

CLIMWAT (n.d.), Retrieved from http://www.fao.org/land-water/databases-and-software/climwatforcropwat/en/.

Cort J. W. (1981), “On the Validation of Models”, Physical Geography 2 (2), 184-194. 
CSA Census Report (1994). Retrieved from http://www.csa.gov.et/component/phocadownload/category/103-census-report.

CSA Census Report (2007). Retrieved from http://www.csa.gov.et/component/phocadownload/category/103-census-report.

Terrestrial Hydrology Group (2014), "Global Meteorological Forcing Dataset for land surface modeling”, Terrestrial Hydrology Research Group, Princeton University. Retrieved from http://hydrology.princeton.edu/data.pgf.php.

Gupta, H. V., Sorooshian S. and Yapo P. O. (1999), "Status of automatic calibration for hydrologic models: Comparison with multilevel expert calibration". J. Hydrologic Eng. 4(2), 135-143.

Halcrow, W. (1989), "Master Plan for the Development of Surface Water Resources in the Awash Basin", Volume II Main Report, Ethiopian Valleys Development Studies Authority EVDSA, Addis Ababa, Ethiopia.

Krause, P., Boyle, D.P. and Base, F. (2005), "Comparison of Different Efficiency Criteria for Hydrological Model Assessment", Advances in Geosciences, 5, 89-97

NASA Earth Observations (NEO), (n.d.), "MODIS Level 2 Cloud fraction Data". Retrieved from http://ftp://neoftp.sci.gsfc.na-sa.gov/geotiff.float/MOD AL2_M_CLD_FR/.

Moriasi, D.N., Arnold, J.G., Van Liew, M.W., Bingner, R.L., Harmel, R.D., Veith, T.L. (2007), "Model evaluation guidelines for systematic quantification of accuracy in watershed simulations", Am. Soc. Agric. Biol. Engineers 50 (3), 885-900.

Nash, J.E. and Sutcliffe, J.V. (1970), "River Flow Forecasting through Conceptual Model: Part 1- A Discussion of Principles", Journal of Hydrology, 10, 282-290.

Parker H., Mosello B., Calow R., Quattri M., Kebede S. and Alamirew T. (2016), “ A thirsty future: water strategies for Ethiopia's new development era", Research reports and studies, Overseas Development Institute, London.

Schneider A., Hommel G., Blettner M. (2010,) "Linear regression analysis: part 14 of a series on evaluation of scientific publications", Dtsch Arztebl Int. 107(44):776-82. Doi:10.3238/ar-ztebl.2010.0776.

SEI (2015), "USER GUIDE for Water Evaluation And Planning System (WEAP)", Stockholm Environment Institute, USA.

Tiruneh Y, Berhanu B, Ayalew S, Tamrat I, Tesfaye Y. (2013), "Synthesis report: Awash River Basin Water Audit", FAO and Ministry of Water and Energy of Ethiopia, Addis Ababa.

WWDSE and WAPCOS, (2005), "Awash River Basin Modelling", Interim Report, Water Works Design and Supervision Enterprise (WWDSE) and Water and Power Consultancy Service (WAPCOS) India LTD. Tendaho Dam and Sugar Project, Addis Ababa, Ethiopia.

Yates, D., Sieber, J., and Purkey, D.(2005), "WEAP 21 - A Demand, Priority, and Preference Driven Water Planning Model, Part-1: Model Characteristics”, Water International, 30, 487-500. 